\title{
CONTRATO E REALIZAÇÃO EM ROUSSEAU
}

\section{ANTONIO CESAR FERREIRA DA SILVA ${ }^{1}$}

RESUMO: Para Rousseau, ao se pensar sobre a estrutura política, é fundamental que se leve em conta a condição humana. Compreender como o homem pôde se realizar fora do contexto natural é compreender que a sociabilidade foi a única via possível para tal intento. Pensar política, pensar sociedade é pensar o homem. E isso Rousseau fez de forma exemplar, partindo sempre da condição que poderia viabilizar a realização do indivíduo; e procurou uma solução a partir da unidade entre aquilo que o homem queria construir para lhe fornecer uma boa condição de vida e aquilo que ele aspirava no seu mais íntimo sentimento, o sentimento de existência. Procurou considerar a vida do homem não dissociando as estruturas do estado em que o homem vivia e as estruturas da sua constituição. Essa via dá unidade ao pensamento rousseauniano, pois é a via que liga suas obras mais sistêmicas às obras de cunho mais antropológico. Daí não se compreender o projeto social de Rousseau sem a ligação com obras que abordam o homem em sua constituição, como é o caso do Discurso sobre a origem e os fundamentos da desigualdade entre os homens. Assim, tratar sobre a melhor forma de sociabilidade é tratar da relação entre essa forma e as aspirações do homem expressas pelo seu sentimento de existência.

PALAVRAS-CHAVE: Rousseau, contrato, realização, reconhecimento.

ABSTRACT: For Rousseau, when thinking about the political structure, it is essential to take into account the human condition. To understand how man was able to fulfill himself outside the natural context is to understand that sociability was the only possible way for such an attempt. Thinking politics, thinking society is thinking man. And that Rousseau did in an exemplary way, always starting from the condition that could make the individual's achievement possible; and he sought a solution based on the unity between what man wanted to build to provide him with a good condition of life and what he aspired to in his most intimate feeling, the feeling of existence. He sought to consider man's life by not dissociating the structures of the state in which man lived and the structures of his constitution. This path gives unity to Rousseau's thought, as it is the path that links his most systemic works to works with a more anthropological nature. Hence, it is not possible to understand Rousseau's social project without the connection with works that approach man in his constitution, as is the case of the Discourse on the origin and the foundations of inequality among men. Thus, to deal with the best form of sociability is to deal with the relationship between that form and the aspirations of man expressed by his feeling of existence.

KEYWORDS: Rousseau, contract, realization, recognition.

\footnotetext{
${ }^{1}$ Professor Adjunto de Filosofia da Universidade Estadual de Feira de Santana (UEFS). Doutor em Filosofia pela Universidade Federal do Ceará (UFC), com período de doutorado sanduíche (CAPES) na Université Charles-deGaulle (Lille 3 - Sciences Humaines et Sociales). E-mail: acesarfsilva@yahoo.com.br.
} 
As palavras de Rousseau que iniciam o primeiro capítulo do livro primeiro do seu $D o$ contrato social emergem com um tom de extrema indignação. Parecendo não se conformar com a condição humana, anuncia que o objetivo desse primeiro livro é apresentar a constituição das sociedades e os problemas dela advindos, sobretudo o fato de a liberdade ter deixado de ser um dos elementos principais da vida humana e de o homem, nesse novo contexto, ter contabilizado mais perdas do que ganhos. Sem a antiga condição, o que poderia ser feito para amenizar os malefícios decorrentes da ordem civil? O homem necessitou de uma nova estrutura para sua vida, e essa nova estrutura se constituiu com a sociabilidade. Mesmo com todos os malefícios da sociedade, Rousseau reconhece que seria impossível ao homem voltar ao passado. Essa nova condição não é oriunda da natureza, mas da ordem das convenções. E o que fez o homem percorrer esse novo caminho? A resposta está contida, como já dito, no seu segundo Discurso.

No primeiro capítulo do seu Do contrato social, Rousseau parece tentar levantar uma dúvida sobre as suas evidências acerca da busca do homem por uma vida grupal, dúvidas que não se confirmam e que remetem o leitor a um elevado grau de curiosidade, curiosidade essa que se dirigirá, sobretudo, para os sentidos do homem em sua nova condição de viver em uma esfera grupal. Se essa esfera grupal surgiu primeiramente com a família e se consolidou com a formação da sociedade civil, um dos elementos centrais da ordem grupal foi o envolvimento dos seus membros com a ordem posta, envolvimento ditado pelo sentimento que cada membro tinha para com a ordem, que era o desdobramento do seu sentimento de existência. Esse sentido que fluía em direção à ordem acabou por confluir para um mesmo ponto, que é o da possibilidade de realizar-se nessa ordem.

No caso do ambiente, Rousseau apresenta o fruto das condições de conservação do homem, a partir daquilo que a natureza podia lhe oferecer. A escassez ou a abundância poderia lhe orientar uma determinada postura. A escassez exigia-lhe, muitas vezes, que uma parceria de outro homem lhe fosse útil. Do ponto de vista da condição humana, da perspectiva do seu sentimento de existência, que é fruto do ambiente, ocorreu uma transformação, pois esse transformar-se fez surgir um novo sentimento, o do amor próprio, sentimento de existência que contribuiu para a gênese da ordem civil. Daqui em diante, se verá como o sentimento de existência foi fundante para a efetivação da ordem e de como ele é o elemento que impulsionou o indivíduo a querer fazer parte dessa estrutura. E por que o indivíduo desejaria fazer parte de uma estrutura que lhe era antagônica? Por que ingressar num contexto que poderia limitar sua liberdade? O limite que lhe foi imposto seria, talvez, mais benéfico do que maléfico? 
A posição de Rousseau quanto à constituição dos agrupamentos humanos é oposta àquela defendida por pensadores e filósofos cujas publicações ele conhecera. No primeiro capítulo de sua obra Do contrato social, ele tece críticas a pensadores como Grotius, Hobbes e até mesmo Aristóteles, para os quais os agrupamentos humanos deveriam conter um grupo específico de homens que conduziriam os demais. Para ele, os que assim se manifestaram, tomaram o direito pelo fato e o efeito pela causa, e assim o fizeram por não terem levado em conta aquilo que é específico da natureza humana. O homem se encontrava numa situação de escravidão, não que tivesse em si a tendência a ser escravo, mas por ter sido levado a essa condição. Se existem aqueles que comandam, os demais foram conduzidos, em certo momento, a serem comandados; e não mais puderam recuperar sua antiga condição de liberdade. Assim, as gerações que não experimentaram a liberdade não poderiam reivindicá-la como algo que lhes fosse inerente, mas apenas por um desejo que não pode ser explicado. Essa condição inviabilizava uma luta mais radical por uma condição de liberdade, que, para nosso filósofo, é também uma condição de direito.

A destituição da condição de liberdade fez emergir um tipo de agrupamento posterior ao agrupamento familiar, cuja constituição foi simultânea ao desenvolvimento de um novo tipo de sentimento de existência. A constituição de uma ordem coletiva, bem como o sentimento de existência que correspondia a essa ordem são tratados por Rousseau a partir de uma análise de todo um processo histórico que explicita essas transformações. Isso fica claro no final da primeira parte do segundo Discurso, em que expõe o caminho que utilizou para demonstrar as mudanças ocorridas no estado de natureza, que deram origem a um novo estado.

A destituição dos últimos vestígios do estado natural, que ocorreu com a luta entre as famílias pela posse da terra levou à procura de um caminho alternativo para a sociedade, que emergira já corrompida. Seria possível ao indivíduo - pergunta Rousseau — recuperar sua condição primeira, dentro de uma dinâmica societária? Sua busca para contemplar as necessidades dos indivíduos, frente à destituição dos últimos vestígios do estado natural, toma como referência os elementos originais da constituição humana. Ele parte da própria natureza humana para considerar a possibilidade de constituição de uma estrutura que substituísse o pacto de submissão. Sua reflexão sobre a aflição dos indivíduos com o fim do estado natural é a própria reflexão sobre a possibilidade de constituição de um projeto social. O pacto social pensado por ele é a resposta às angústias dos indivíduos que perderam a segurança do estado natural. Sem a estrutura natural, o que os indivíduos deveriam construir para suprir esse estado? O que fazer sem a estrutura que tudo fornecia e com a qual se podia ser feliz? 
O contrato rousseauniano tem, assim, duas dimensões: a dimensão sistêmica e a dimensão existencial do indivíduo. A primeira é relativa à estrutura da ordem civil, na qual se define a estrutura da república e sua funcionalidade, a estrutura da república e a viabilidade do seu funcionamento, com os elementos que correspondem à organização, às leis, aos órgãos colegiados, aos componentes dos órgãos e à dinâmica do poder. A dimensão existencial do pacto é relativa aos aspectos que envolvem os indivíduos entre si, que se desdobrará na adesão a um modelo de vida coletiva, adesão a um modelo de estrutura política. Nesse aspecto, tem-se como centro o sentimento de existência dos indivíduos que iria nutrir a vida em grupo. Nessa face da vida republicana, destaca-se a transição do amor próprio para o amor à pátria. $\mathrm{O}$ sentimento de existência é fundamental para a compreensão do componente central da ordem sistêmica do contrato rousseauniano, a vontade geral, dissipando-se qualquer análise de anulação das individualidades. Primeiramente, veja-se a constituição do contrato, em seu aspecto estruturante.

A primeira reflexão sobre a abordagem estruturante do contrato rousseauniano é relativa ao seu aspecto antropológico. Isso significa que a sistematicidade do contrato tem como fundamento o homem, o indivíduo em sua constituição. Assim, o contrato não se estrutura a partir de algo que é exterior ao próprio homem, mas parte de sua constituição enquanto homem. Do contrário, ter-se-ia o desdobramento de uma estrutura meramente sistêmica, à qual o indivíduo deveria se enquadrar. Seria uma mera inserção em uma estrutura que atenderia os desejos do indivíduo, mas que lhe seria exterior. Ao contrário, a estrutura do contrato bem como a política rousseauniana são oriundas da própria natureza dos indivíduos, da sua própria humanidade. O contrato é uma resposta a uma questão colocada pelos indivíduos, e não uma questão que lhes é exterior, como fica claro no trecho a seguir:

Quero indagar se pode existir, na ordem civil, alguma regra de administração legítima e segura, tomando os homens como são e as leis como podem ser. Esforçar-me-ei sempre, nessa procura, para unir o que o direito permite ao que o interesse prescreve, a fim de que não fiquem separadas a justiça e a utilidade (p. 21). ${ }^{2}$

Além de estar clara em sua obra, essa posição é defendida por intérpretes seus, para os quais a política e a antropologia não estão separadas embora sejam disciplinas distintas. ${ }^{3}$ Ora, a efetivação do contrato é aquilo que, na prática, serve como estrutura que propicia ao indivíduo

\footnotetext{
${ }^{2}$ Doravante, de todas as citações da obra Do contrato social serão indicadas apenas as páginas em que se encontram na tradução de Lourdes Santos Machado para o português, em sua quarta edição (São Paulo: Nova Cultural, 1987).

3 "De fato, a filosofia política se refere à antropologia como uma disciplina sobre a qual ela se funda, mas também como uma disciplina distinta. É o sentido do primeiro parágrafo do capítulo um do Contrato" (VINCENTI, 2000, p. 6-7, Tradução nossa).
} 
o suporte para sua vida. No contrato, o indivíduo encontra sua moradia e tudo aquilo que uma moradia pode fornecer. O contrato é o abrigo criado pelo indivíduo e o protege de tudo e de todos ao mesmo tempo. É a garantia de uma vida plena, na medida em que tem a garantia de sua livre manifestação. O contrato em Rousseau levou à categoria do direito os componentes da constituição natural do homem indivíduo, sobretudo pela possibilidade da ideia de justiça. Tem-se, logo no início do contrato, o anúncio do que Rousseau pretendia ao formular sua ideia de contrato social: "a unidade entre os componentes estruturantes e os componentes existenciais e naturais" (p. 21). Essa unidade lhe possibilita formular uma ideia de contrato que está para além da questão clássica em filosofia política, entre a liberdade do indivíduo e a liberdade civil. Ele não resolveu essa questão, mas quis estar para além da mesma, o que significa que a questão central de suas preocupações é a realização do indivíduo. O contrato seria, assim, uma resposta necessária e urgente ao que o indivíduo passou a aspirar, isto é, a possibilidade de se realizar fora da esfera natural. A questão da realização extrapola a tensão entre o indivíduo e o coletivo e se sobressai, sobretudo quando aborda a perspectiva da vontade geral. Como obedecer a um todo e, ao mesmo tempo, continuar livre é uma discussão que leva a um círculo vicioso, que, ao final, induziu extremistas a enquadrarem Rousseau ora no campo liberal, ora no campo do totalitarismo. Esse tipo de equívoco é fruto de uma leitura fragmentada dos que se apegam a uma ou outra passagem de suas obras. No entanto, ao se conhecer o horizonte de fundamentação rousseauniano, centrado sobretudo na ideia de realização, compreende-se o que, de fato, ele almejava em suas reflexões.

Logo no início do primeiro capítulo, do livro I, a já conhecida passagem dos leitores assíduos do seu Do contrato social demonstra todo seu esforço em resolver o problema antes apontado em seu segundo Discurso:

O homem nasce livre, e por toda a parte encontra-se a ferros. O que se crê senhor dos demais, não deixa de ser mais escravo do que eles. Como adveio tal mudança? Ignoro-o. Que poderá legitimá-la? Creio poder resolver esta questão (p. 22).

A condição de dependência de uns homens em relação aos outros não significa a existência da liberdade e da realização por parte de alguns homens, pois nem mesmo os que dominavam tinham disponível para si o mundo da liberdade. Nem senhores nem escravos podiam usufruir da plena realização. Ninguém se realizava, pois a constituição da vida entre os homens era a da dependência de todos para com todos. Onde Rousseau, encontrou a solução para o problema da dependência do homem? Qual o fundamento, o princípio que norteou suas respostas? 
Para muitos que, de forma apressada, interpretam Rousseau, a saída estaria em uma sociedade cujo suporte seria a simples criação de normas, o que a muitos deu a entender que seu horizonte de fundamentação se deslocara da natureza para uma formulação de normas que estariam para além dessa mesma natureza. A passagem que se segue serve de sustentação para leitores que admitem o abandono de Rousseau de seu horizonte primeiro, o da natureza:

A ordem social, porém, é um direito sagrado que serve de base a todos os outros. Tal direito, no entanto, não se origina da natureza: funda-se, portanto, em convenções. Trata-se, pois, de saber que convenções são essas (p. 22-23).

A impressão que, à primeira vista, se poderia ter é a do abandono do universo da natureza, porém ele procura exprimir que, de fato, a nova ordem social, tem uma outra dinâmica de funcionamento, diferente daquela do estado natural. Não que isso signifique o esvaziamento da discussão desenvolvida pelo segundo Discurso. O que há, de fato, e pode ser constatado em todo esse seu texto, é que a nova ordem se utiliza de convenções que não eram da ordem natural. Ora, se o homem é o criador dessa nova ordem, as convenções não atenderiam as demandas da ordem puramente natural. No entanto, aquilo que esta nova ordem almeja nada mais é do que o resgate do fundamento da vida do homem, do que se encontra em sua vida mais remota. Isso significa que a nova ordem deve estabelecer o equilíbrio da antiga ordem, mas sem a sua estrutura. A ordem social deve resgatar a liberdade, ou seja, o que existe de mais profundo no homem é que servirá de horizonte para a nova ordem. É, portanto, o próprio homem o horizonte que funda o pacto e a ordem social rousseauniana. Não há como fugir a isso. As convenções, portanto, não são as mesmas da ordem natural, embora sua fundamentação encontre seu suporte naquilo que é natural, o próprio homem. Como isso poderia se dar?

Primeiro, apesar de ter saído do estado natural, o homem levou consigo sua constituição originária, que, se não mais predominava sobre si, é porque o homem se deixou seduzir por outra dinâmica de vida que levou ao arrefecimento de sua condição primeira. Segundo, o contrato é uma resposta aos anseios mais primitivos do homem, os anseios de bem-estar, que fomentará a sua realização. Em toda e qualquer ordem que o homem experimentou em sua vida, ele sempre buscou a sua realização, que está ligada ao que tem de mais profundo, o seu sentimento primeiro, o amor de si. Na nova ordem, porém, esse sentimento primeiro não se manifestou como no estado natural, pois estava em hibernação. O que predominou, inicialmente, na ordem civil foi o princípio do amor próprio, o qual Rousseau procura transformar em sua nova proposta de ordem. 
Assim, a obra Do contrato social só pode ser considerada a partir do próprio homem enquanto horizonte de referência; não um tipo específico de homem, mas de todos os homens, pois todos possuem uma mesma constituição. Essa posição de Rousseau levou-o a fundamentar sua oposição à escravidão e ao direito do mais forte, já elaborada pelos princípios que adotou no segundo Discurso. Não havia homens com uma constituição e homens com outra constituição, homens superiores e homens inferiores, homens detentores de uma razão superior e homens detentores de uma razão inferior. Essa mesma constituição seria o fundamento daquilo que o homem construiria, e que visaria a atender seus anseios de realização.

No segundo capítulo do livro I do seu Do contrato social, Rousseau tece críticas tanto a Grotius, quanto a Hobbes, para os quais existe uma centena de homens aptos a conduzir os demais, que nada mais seriam do que um bando que precisa ser orientado e guiado.

Resta, pois, em dúvida, segundo Grotius, se o gênero pertence a uma centena de homens ou se esses cem homens pertencem ao gênero humano. No decorrer de todo o seu livro parece inclinar-se pela primeira suposição, sendo essa também a opinião de Hobbes (p. 24).

A natureza humana é a mesma em todos os homens; apesar das diferenças entre eles, sua constituição primeira é idêntica. O que ocorre é a possibilidade de alguns homens adquirirem determinadas habilidades, em decorrência do seu contexto de vida, como, por exemplo, a aceitação da escravidão, embora ela seja contrária à própria natureza humana. E assim se manifesta sobre Aristóteles:

\begin{abstract}
Aristóteles tinha razão, mas tomava o efeito pela causa. Todo homem nascido na escravidão, nasce para ela; nada mais certo. Os escravos tudo perdem sob seus grilhões, até o desejo de escapar deles; amam o cativeiro como os companheiros de Ulisses amavam o seu embrutecimento. Se há, pois, escravos pela natureza, é porque houve escravos contra a natureza. A força fez os primeiros escravos, sua covardia os perpetuou (p. 24-25).
\end{abstract}

Há, no trecho acima, uma explicação que já estava contida no segundo Discurso. Embora haja diferença entre o homem do segundo Discurso e o homem do seu Do contrato social, há algo que lhes é comum, ou seja, a sua natureza primeira. A escravidão, decorrente de um contexto de desigualdade e de força é abordada como algo que não é da estrutura do homem; nada mais é do que a degradação da própria condição do homem. Quando da submissão do homem ao direito daquele que lhe era mais forte, ocorreu apenas o exercício da própria sobrevivência, do contrário, acabaria sucumbindo diante daquele poder. Contra as estruturas escravocratas Rousseau levanta sua voz, propondo um tipo de estrutura que possibilitará atender as aspirações mais profundas da natureza humana. Não sendo mais viável a vida nas florestas, cabe pensar em uma alternativa para o mundo construído pelo homem, não havendo, porém, espaço concreto para uma ruptura com a nova forma de vida do homem, a vida coletiva. Seria 
possível ao indivíduo realizar-se em uma coletividade? E em que tipo de estrutura? Desta forma, se debruça sobre a possibilidade de construção de uma alternativa de vida em grupo.

Pode-se buscar a resposta a partir daquilo que Rousseau nega veementemente - a condição de escravidão - já acenada no segundo Discurso e consolidada no quarto capítulo da primeira parte do seu Do contrato social. A força não gera direito e, assim, ele abomina a escravidão, que se fundamenta na força. Ao rejeitar a escravidão, nega a posição da escola do direito moderno, da qual um dos principais representantes é Grotius, assim citado por Rousseau "Se um particular, diz Grotius, pode alienar sua liberdade e tornar-se escravo de um senhor, por que não o poderia fazer todo um povo e tornar-se súdito de um rei?"” (p. 26):. Segundo essa postura, um homem poderia se dar a outro homem de forma plena. Ao analisar a afirmação de Grotius, o filósofo genebrino nos mostra que o termo "alienar" é a própria negação daquilo que o homem possui de mais profundo, a sua liberdade. Alienar-se, em Grotius, é abdicar de sua natureza, daquilo que o homem é. Essa maneira de conceber uma forma de direito ratifica a submissão de todo e qualquer indivíduo, assim como de toda e qualquer sociedade às determinações de um monarca ou déspota. Mesmo que um indivíduo ou até mesmo um povo optassem por abdicar de sua liberdade, isso se assemelharia à loucura. Assim como a força não gera direito, a loucura também não. Alienar-se à condição de escravidão seria desfazer-se, primeiramente, da condição de homem e, posteriormente, da de indivíduo, o que seria impraticável e apenas sob o ditame da violência poderia se estabelecer. Abdicar da condição de homem seria negar qualquer vestígio natural, negar a condição de liberdade inerente ao indivíduo, que não se pode extrair de sua natureza.

Mesmo quando cada um pudesse alienar-se a si mesmo, não poderia alienar seus filhos, pois estes nascem homens e livres, sua liberdade pertence-lhes e ninguém, senão eles gozam do direito de dispor dela. Antes que cheguem à idade da razão, o pai, em seu nome, pode estipular condições para sua conservação e seu bem-estar, mas não pode dá-los irrevogavelmente e incondicionalmente, porque uma tal doação é contrária aos fins da natureza e ultrapassa os direitos da paternidade (p. 27).

O máximo que poderia ocorrer seria o seu arrefecimento em decorrência das circunstâncias da vida, como no caso daquele que nasceu sob a égide da escravidão. A liberdade é uma condição da vida do indivíduo e não pode ser negociada ou alienada. Rousseau deixa claro: "Renunciar à liberdade é renunciar à qualidade de homem, aos direitos da humanidade, e até aos próprios deveres" (p. 27).

Dessa forma, a liberdade é elevada à categoria do direito, nasce da própria constituição do indivíduo rousseauniano, abrindo espaço para a fundamentação da sua concepção de pacto social. Assim, vê-se que o pacto rousseauniano tem uma ligação profunda com o segundo Discurso. Se este último gira em torno da constituição primeira do homem, que tem como um 
de seus elementos a liberdade, o pacto utiliza-se dessa mesma liberdade para a autoafirmação do indivíduo.

Além de rejeitar elementos da força e da loucura como componentes para a fundamentação do direito nas teorias do direito natural moderno, ele repele também a fundamentação do direito a partir dos desdobramentos da guerra. A guerra não pode gerar direito, pois seus vencedores não podem barganhar o controle dos vencidos pela manutenção de suas vidas. A vida do homem, bem como sua liberdade, não pode servir como moeda de troca, pois a negação da liberdade é a negação da própria vida. E o que se evidencia por esta via do direito natural moderno é que a força se impõe ao indivíduo. Além disso, a guerra não é realizada entre dois indivíduos, mas é fruto do embate entre dois seres de coletividade, diz respeito ao ser moral coletivo. Não se trata, portanto, do simples embate ou de uma briga entre dois indivíduos particulares, mas de uma relação entre dois estados (p. 28). Por ser um conflito entre dois estados e em um contexto de força, a guerra não pode gerar o direito, não podendo, portanto, usurpar a liberdade de nenhum indivíduo.

Os primeiros capítulos do livro I de sua obra Do contrato social fundamentam sua ideia de contrato, um contrato social que possibilitasse ao homem sua realização. Desse modo, defende a não aceitação de qualquer tipo de coerção para a criação e fundação de um pacto social. O contrato social deveria partir do indivíduo livre, e só teria sentido se servisse de amparo para esse indivíduo, pois o direito que rege seu contrato se sustenta na própria liberdade do indivíduo. O pacto rousseauniano busca uma estrutura que possibilite ao indivíduo a sua realização e inaugura sua busca dentro do viés da possibilidade. Não há a determinação de que certo tipo de solução seja de forma definitiva. O que é de fato definitivo para Rousseau é a própria busca por um caminho que possa viabilizar a realização do indivíduo. O roteiro encontrado é um roteiro de possibilidade que procura responder à questão: é possível encontrar uma estrutura que permita ao homem sua plena realização? Essa é uma questão que se arrasta desde sua formulação sobre as origens do homem, e sobre a origem das desigualdades entre eles. A questão da possibilidade em torno da melhor estrutura possível para que o homem se realize encontra-se na sua própria formulação sobre o contrato, sobre a efetivação de uma forma de associação. Eis um trecho bastante conhecido:

\footnotetext{
Encontrar uma forma de associação que defenda e proteja os bens de cada associado com toda a força comum, e pela qual cada um, unindo-se a todos, só obedece a si mesmo, permanecendo assim tão livre quanto antes (p. 32).
}

Do ponto de vista prático, a associação que se constitui em estruturas é uma espécie de invólucro de proteção, funda o novo lar do indivíduo. Tendo perdido seu primeiro abrigo - a 
natureza - o indivíduo se encontrou indefeso, e a sociedade foi aquilo que pôde criar para atender sua necessidade de realização. No caso do indivíduo cidadão, sua realização passa pela questão do reconhecimento.

Antes de tratar da realização e do reconhecimento, é preciso deixar claro o que é fundamental para a proposição rousseauniana de pacto social. O que deseja Rousseau? Pela citação acima, o centro da questão seria encontrar para os indivíduos a melhor estrutura possível, que lhes deveria propiciar uma boa condição de vida. Rousseau conclui que a vida de associação é a melhor alternativa para o indivíduo, uma vez que viver em grupo tornou-se fundamental para a superação dos conflitos advindos da desestruturação da vida natural. Nesse sentido, ele não traz nenhuma novidade. Outros, como os defensores do direito natural moderno e pensadores anteriores a Rousseau, defenderam a vida pública como a melhor forma para aplacar a índole brutal e violenta dos homens. Nesse sentido, Rousseau está em consonância com a tese de Pufendorf, Hobbes, Locke, Grotius, etc. Todos também estão unidos em torno da ideia de que a vida social é uma espécie de abrigo para o homem. Entretanto, dois componentes distanciam Rousseau desses teóricos. O primeiro é o de que a liberdade é elevada à categoria de fundamento do direito; o segundo é o de que o contrato rousseauniano se encontra numa perspectiva de possibilidade.

Sobre o primeiro componente, já aqui comentado em outras passagens, Rousseau considera que o homem foi corrompido e, em decorrência dessa corrupção, teve sua liberdade destruída. Como o homem não nasce corrompido, nem escravo, a sociedade proposta por Rousseau deve possibilitar aos indivíduos a sua recuperação, o seu restabelecimento; deve, de certa forma, recuperar em parte aquilo que perdeu com o fim do estado natural. Diz-se em parte, porque o nosso filósofo conhece os limites da vida em sociedade e sabe que a antiga condição de liberdade não pode ser restaurada plenamente. A possibilidade de recuperação se encontra na constituição de uma vida de associação, que tem na liberdade o expoente central de sua fundamentação legal, reconhecendo, porém, os limites que advêm da vida associativa. O direito de tal associação tem como ponto de partida a liberdade do indivíduo, que é negada por pensadores e jurisconsultos que o antecederam.

O segundo componente, o da possibilidade, está posto no trecho acima citado "Encontrar uma forma de associação [...] tão livre quanto antes" (p. 32). O verbo encontrar traz o significado de busca, de procura, não apenas no sentido de ir atrás de algo perdido, mas também de ter de criar. O procurar, o buscar têm o sentido da própria criação. O texto original em francês, assim se inicia: "Trouver une forme d'association [...]” (ROUSSEAU, 1959, v. 3, 
p. 360.) Trouver origina-se, provavelmente, do latim popular tropāre, derivado de tropus. Tem, inicialmente, o sentido de 'criação', de ‘composição', e também o de 'invenção', além de outros significados construídos ao longo do tempo. ${ }^{4} \mathrm{O}$ sentido que carrega a perspectiva de Rousseau é o de 'criação', daí seu contrato poder ser visto como um pacto de possibilidade, algo que não se encerra em uma estrutura fechada.

A estrutura do pacto rousseauniano não tem um fim em si mesmo, mas tem uma finalidade em função da realização do indivíduo, tem a função de garantir ao homem proteção e conservação. No capítulo V, livro II do seu Do contrato social, enfatiza, mais uma vez, a questão do direito de conservação do indivíduo, como também a construção de uma estrutura social que pode levá-lo a inúmeros riscos, pois sua construção está no campo das possibilidades, no campo do imprevisível. Refere-se ao direito de vida e morte, mostrando que as dificuldades de se compreender esse direito parte do tipo de colocação que envolve a questão.

Todo homem dispõe do direito de arriscar sua própria vida para conservá-la. Jamais se disse, daquele que se lança por uma janela para escapar a um incêndio, que seja culpado de suicídio? Jamais se atribuiu tal crime àquele que perece numa tempestade cujo perigo não ignorava ao embarcar? (p. 51).

O tratado social busca, de fato, a proteção dos contratantes. Note-se que, no texto, ele se refere à conservação dos homens. Conservar pode ser visto também com o sentido de se garantir a melhor condição dos contratantes, dos indivíduos-cidadãos, que traz riscos inevitáveis para todos os seus construtores, dos quais devem ter consciência. Para Rousseau, o que está em jogo é a condição e a segurança dos homens, e isso se evidencia, na medida em que discursa sobre o direito de viver e de morrer:

Quem deseja os fins, também deseja os meios, e tais meios são inseparáveis de alguns riscos e, até, de algumas perdas. Quem deseja conservar sua vida à custa dos outros, também deve dá-la por eles quando necessário (p. 51-52).

Assim, todo trabalho de construção visa à garantia de proteção dos membros do estado, visa à garantia da realização dos membros da república. Além de propiciar ao indivíduo um abrigo, um lar, uma proteção, coloca-o numa nova condição, a condição de indivíduo cidadão, na qual a dependência deixa de existir. Se, com o fim do estado natural e com a emergência da vida civil, o indivíduo encontrou-se na condição de dependência, o indivíduo cidadão passaria a gozar de plena independência. O que significa tal independência? Em uma nova sociedade, o indivíduo cidadão pode recuperar sua liberdade roubada pela desigualdade entre os homens, a

\footnotetext{
${ }^{4}$ Dictionnaire étymologique de la langue française. Sous la direction de Oscar Bloch et W. von Wartburg. Paris: Presses Universitaires de France, 1964. p. 654.
} 
qual sucumbiu com o fim do estado natural. Não haveria mais uma relação de dependência interindividual, pois, para se realizar, o indivíduo deveria estar imerso em uma vida contratual, em um contrato em que todos os indivíduos-cidadãos estivessem comprometidos com uma vida de solidariedade mútua, sem que existisse a relação senhor- escravo, como foi bem descrito no segundo Discurso. Sem a dependência interindividual, todos os indivíduos poderiam se realizar. Dessa forma, pode-se fugir da armadilha que envolve muitos leitores sobre o individualismo ou sua negação por parte de Rousseau. A questão que envolve o indivíduo e sua relação com a coletividade é típica da filosofia política, e parece não haver uma solução definitiva. Rousseau não é um mero individualista, tampouco um mero coletivista. A questão central de Rousseau envolve a preocupação com a condição do indivíduo. É sobre ele que Rousseau volta seu olhar. O contrato é uma tentativa de encontrar (trouver), como Rousseau pensou, uma estrutura que possibilitasse ao indivíduo sua realização e sua felicidade. $\mathrm{O}$ contrato não tem um fim em si mesmo, só tem sentido por causa do indivíduo cidadão, do ser humano. Daí que o contrato deve ser tratado sob a ótica da possibilidade.

Os limites do contrato em Rousseau são visíveis, e não poderia ser diferente. Todo e qualquer contrato de sociabilidade evidencia seus limites. Em Do contrato social, sexto capítulo do livro I, um trecho serve de combustível para alimentar as críticas a Rousseau quanto ao seu anti-individualismo. Veja-se:

\footnotetext{
Essas cláusulas, quando bem compreendidas, reduzem-se todas a uma só: a alienação total de cada associado, com todos os seus direitos, à comunidade toda, porque, em primeiro lugar, cada um dando-se completamente, a condição é igual para todos, e sendo a condição igual para todos, ninguém se interessa por torná-la onerosa para os demais (p. 32).
}

A experiência com a formulação de uma proposta de contrato, como em todos os outros autores da filosofia política moderna, não poderia deixar de pontuar limites à ação do indivíduo, à sua liberdade. E Rousseau não foge a essa perspectiva, na medida em que é também herdeiro da tradição da filosofia política que o antecedeu e que considerou o contrato social como o espaço para resolver os problemas dos conflitos entre os indivíduos. Entretanto, em que medida Rousseau se afasta dessa tradição no que diz respeito aos indivíduos e sua liberdade? Primeiro, deve-se reconhecer que o contrato rousseauniano contém limites à manifestação plena do indivíduo. A citação acima confirma os limites com os quais os indivíduos deveriam saber vivenciar. E Rousseau teve plena consciência dos limites do seu contrato, quanto à situação dos indivíduos. Isso se confirma, tanto pelo anúncio inicial da fórmula do contrato, com a qual o indivíduo tem garantida sua liberdade, como também pela adesão do indivíduo a uma cláusula que lhe requer alienação. Tem-se, dessa forma, a tentativa de Rousseau de pensar a 
sociabilidade conservando-se a liberdade do indivíduo e, ao mesmo tempo, sua alienação à cláusula que o convoca a viver em comunidade. Como afirmado anteriormente, o contrato rousseauniano é a expressão da constituição do próprio indivíduo. Ele é decorrente da liberdade do indivíduo transformada em fundamento do direito, como também é fruto do ensaio proposicional de um modelo de vida social. Tem-se, nesse sentido, uma via que decorre dos sentimentos do indivíduo, e outra via que é decorrente de uma proposição racional. O contrato é pensado a partir dessas duas vias, com predominância da primeira. Dessa forma, não se pode encarar Rousseau dentro dos limites de seus antecessores, nem dentro dos limites que lhe foram atribuídos por pensadores contemporâneos que lhe imputaram a pecha de ter proposto um estado totalitário, no qual o indivíduo praticamente desapareceria. $\mathrm{Na}$ verdade, nesses casos, não se compreendeu o contrato rousseauniano dentro do contexto de sua obra, atendo-se, provavelmente, a passagens isoladas, deixando-se de perceber que o centro de sua preocupação foi a condição do indivíduo. O contrato social rousseauniano é a tentativa de responder a questão que segue. Como se podem resolver os problemas dos indivíduos que foram destituídos do estado natural? Seu contrato não se situa na esfera da pura elaboração, mas tem seu solo no próprio indivíduo.

Para fugir a qualquer tipo de interpretação extremista do contrato de Rousseau é necessário compreender o espírito do seu contrato, compreender o indivíduo rousseauniano. Para Rousseau, o indivíduo vivia massacrado pelo contexto da desigualdade. Usando uma expressão de Eric Weil (1971, p. 93): “L’individu dans la société moderne est essentiellement insatisfait”, ou seja, o indivíduo moderno é um ser inteiramente descontente com sua vida, não desfruta dos bens necessários tampouco é feliz. Rousseau esteve atento a esse clamor do indivíduo moderno, do indivíduo de seu tempo, esteve atento ao seu próprio clamor enquanto indivíduo e, assim, transformou o indivíduo no horizonte fundamental do seu contrato social. A forma como Rousseau indica o horizonte do seu contrato inibe qualquer perspectiva de violência por parte do estado em relação ao indivíduo. Na concepção rousseauniana, o estado não deveria produzir violência contra o indivíduo — como os estados totalitários do século XX —, pois, o estado só tem vida e sentido em função da realização do indivíduo. A primeira medida da vida civil para atender os interesses do indivíduo seria a que põe fim à desigualdade, cujo desdobramento seria o fim da oposição entre os indivíduos. Desse modo, seu contrato social visa a exterminar a oposição entre os indivíduos e não a manifestação dos indivíduos. O espaço criado para a vida dos indivíduos seria o espaço em que o conflito constante tem fim, e no qual os indivíduos podem se manifestar dentro do acordo firmado. Isso quer dizer que, ao se 
acabar com a oposição entre ricos e pobres, senhores e escravos, os indivíduos passariam a ser livres. Essa liberdade - a liberdade civil — poria um termo à dependência entre os indivíduos. Diferentemente do modelo de sociedade desigual, os indivíduos passariam a agir em função daquilo construído por todos, que é o contrato. Desse modo, submeter-se ao contrato seria submeter-se a si próprio, submeter-se ao pacto do qual ele seria um dos artífices. Embora a liberdade de um indivíduo não se sobressaia sobre outro, isso não significa o fim da individualidade, mas o fim da dependência. A concepção do pacto de Rousseau livraria o indivíduo da dependência construída pelos antigos contratos que tinham no amor próprio sua manutenção.

Enfim, cada um dando-se a todos não se dá a ninguém e, não existindo um associado sobre o qual não se adquira o mesmo direito que se lhe cede sobre si mesmo, ganhase o equivalente de tudo que se perde, e maior força para conservar o que se tem (p. $33)$.

Ao aderir ao pacto, o indivíduo não se daria a nenhum outro indivíduo, mas a si mesmo, pois se entregaria a uma obra que também seria sua. Tem-se assim, com Rousseau, uma fórmula para se manter a integridade do indivíduo, que não recebe um pacto pronto, mas dele é o principal artífice e, assim sendo, ele se submeteria às regras que ele próprio forjou e, também, aos perigos de sua obra. Os perigos são reconhecidos por Rousseau, mas qualquer busca de construção traz consigo os perigos da empreitada. A questão é que, para o nosso filósofo, a busca pela melhor fórmula para a construção do pacto é a da possibilidade. A possibilidade que é da constituição da própria natureza do indivíduo. Do contrário, o pacto seria apenas uma forma de controle que poderia reduzir o indivíduo a uma mera fração da composição da ordem estabelecida.

Para evitar que o indivíduo se transformasse em uma mera fração da ordem, Rousseau pensou naquilo que é a inspiração que norteia os desejos dos indivíduos no campo da vida comunitária: a vontade geral, que é a síntese do envolvimento de todos os indivíduos em torno do bem comum. Aquilo que impulsiona os indivíduos a edificar uma estrutura social tem como elemento condutor seu desejo de partilhar a constituição do bem de todos. A vontade geral não seria uma mera soma das vontades dos indivíduos, não seria o mero somatório de desejos idênticos, mas a vontade de partilhar o espírito de colaboração e de solidariedade. Nesse sentido, a vontade geral se esmera para garantir a perpetuação da vida boa e da vida livre de todos os cidadãos, onde ninguém é escravo de ninguém, mas onde todos formam uma rede de colaboração que será vivenciada nas estruturas do pacto. Garante-se, dessa forma, a liberdade de todos dentro do contexto, que seria, então, a vida social. 
[...] o pacto fundamental, em lugar de destruir a igualdade natural, pelo contrário substitui por uma igualdade moral e legítima aquilo que a natureza poderia trazer de desigualdade física entre os homens, que, podendo ser desiguais na força ou no gênio, todos se tornam iguais por convenção e direito (p. 39).

Não há, no contrato rousseauniano, uma oposição entre o indivíduo e a coletividade, mas, sim, uma relação de tensão, que é inevitável e se efetiva com os limites estabelecidos pela vida comum. A partir do sentimento de existência, o indivíduo projeta-se sobre um novo modelo de vida, o da vida coletiva. A vontade geral seria, assim, a deflagração do compromisso de todos os indivíduos com a vida comum, e todos os indivíduos deveriam estar envoltos pela dinâmica da vontade geral, em busca do bem comum. A vontade geral não se efetivaria a partir de uma pura atividade metafísica, mas a partir do sentimento de existência dos indivíduos:

A primeira e a mais importante consequência decorrente dos princípios até aqui estabelecidos é que só a vontade geral pode dirigir as forças do Estado de acordo com a finalidade de sua instituição, que é o bem comum, porque, se a oposição dos interesses particulares tornou necessário o estabelecimento das sociedades, foi o acordo desses mesmos interesses que o possibilitou (p. 43).

Se a compreensão da vontade geral de Rousseau foi interpretada como um mecanismo para sufocar o indivíduo é que se fez uma leitura parcial e/ou pontual de sua obra. Rousseau inova na compreensão sobre as raízes da vontade geral, distanciando-se sobretudo de Diderot, que adotou como referência a compreensão de indivíduo dividido, de indivíduo partido. Os indivíduos divididos teriam uma dimensão boa e uma dimensão má, e a sociedade viria banir, com suas estruturas, o lado mau dos indivíduos. Segundo Luc Vincenti (2001, p. 141-142), Rousseau evita a compreensão adotada por Diderot:

Rousseau recusa a existência de uma sociedade geral do gênero humano, no seio da qual os comportamentos são regidos e o egoísmo natural corrigido por uma vontade geral a que os indivíduos chegariam [...]. Rousseau recusa não somente a existência de uma benevolência persistente que compensaria o egoísmo do indivíduo depravado, mas também a ideia de que esta benevolência pudesse, sob a forma da vontade geral proposta por Diderot, reger efetivamente esta hipotética sociedade geral (tradução nossa). ${ }^{5}$

Ora, esse tipo de compreensão reforça a ideia de que o estado é um ente que emerge para a salvação do indivíduo, um ente que eclode com uma força superior ao indivíduo para purificá-lo de todo e qualquer tipo de mal, compreensão que serviu para alimentar a ideia contemporânea de estados totalitários.

\footnotetext{
5 "Rousseau recuse l'éxistence d'une société générale du genre humain, au sein de laquelle les comportements sont régis et l'égoisme naturel corrigé par une volonté générale que les individus trouveraient [...]. Rousseau récuse non seulement l'existence d'une bienveillance persistante qui compenserait l'égoisme de l'individu dépravé, mais aussi l'idée que cette bienveillance puisse, sous la forme de la volonté générale proposée par Diderot, régir effectivement cette hypothétique société générale."
} 
Rousseau indica, porém, um outro caminho para a constituição do estado. Diferentemente de Diderot, a vontade geral em Rousseau leva em consideração a constituição do próprio indivíduo, sobretudo o amor de si, observação feita por Vincenti (2001, p. 142), para quem o amor de si tem um papel fundamental na filosofia política de Rousseau, destacando que nesse ponto está sua originalidade. Seu projeto de contrato é oriundo de seu sentimento de existência que é expresso pelo amor de si, que não se destruiu, mas ficou hibernando no interior do indivíduo, depois de ter sido tomado pelo sentimento do amor próprio. $\mathrm{O}$ amor de si o conclama a se realizar e, com o pacto, aponta para uma realização coletiva.

O estado rousseauniano - a república - tem vida e sentido graças aos indivíduos, e não tem a tarefa de controlá-los, como para Diderot, mas, sim, de lhes servir de abrigo. O estado não proporcionaria a realização dos indivíduos, mas seria o espaço no qual se daria essa realização. Sua concepção de estado se diferencia da dos demais pensadores de sua época, justamente por não ser o estado o ente que salvaria o indivíduo de suas mazelas.

Em que Rousseau se fundamenta para propor uma república, que não seja um elemento externo ao indivíduo, mas um elemento que se constitui a partir desse mesmo indivíduo? Mas de onde se origina a compreensão de um estado salvador dos indivíduos? Essa é uma questão que deve ser abordada.

Como dito anteriormente, Rousseau se distancia de Diderot quanto à concepção de indivíduo. Enquanto em Diderot o indivíduo se encontra partido, a oposição entre paixões e razão proporcionaria uma concepção de estado dirigente e protetor da vida dos indivíduos, o que forneceu ao Ocidente a visão extremista de modelos autoritários e totalitários. Nessa divisão do indivíduo, a vontade geral e a razão se sobrepõem aos seus sentidos, e o estado emerge como uma estrutura que salvará o homem. Algo que é distante e distinto da condição do indivíduo, já que são instâncias puras a salvar o indivíduo impuro. Se há uma divisão do indivíduo entre sua dimensão racional e sua dimensão dos sentimentos, tem-se uma supremacia de uma das dimensões. Os leitores tradicionais de Rousseau dão ênfase ao racional sobre o lado sensitivo. O racional surge como o mecanismo que deverá conduzir o homem pelo melhor caminho. Seria o lado racional do homem que poderia conduzir o indivíduo ao mundo civilizado, ao mundo do pacto. Dessa forma, pode-se justificar a estrutura do estado protetor como um ente externo ao indivíduo. Esse tipo de concepção do indivíduo serve de fundamentação para esse modelo de estado interventor. Como o indivíduo é concebido de forma partida, o desdobramento disso na constituição do estado é a total dependência do indivíduo. Se, por um lado, tem-se a razão, por outro, tem-se a sensibilidade. Assim, em correspondência tem-se o estado e o indivíduo. 
Aquele, portador da racionalidade que guia. O segundo deve-se deixar guiar pelas luzes da racionalidade. Limitado pela dinâmica das paixões, o indivíduo deve entregar-se aos ditames do estado.

Toda essa dependência do indivíduo ao estado é fruto de uma concepção que Rousseau rejeita, e que se constata em sua crítica a Diderot, que deu à razão um papel fundamental para a constituição de vontade geral. A vontade geral tendo na racionalidade o seu único ponto de apoio, se desdobra sobre os indivíduos como algo que também lhes vem de fora. A vontade geral emerge como uma força que está para além das vicissitudes dos indivíduos, e aquilo que lhe deu força é apenas algo que agora deve proteger. Ela é a guardiã dos interesses comuns aos indivíduos e foi constituída como uma arma contra as ameaças oriundas dos desejos particulares. Ora, isso é possível em Diderot graças à sua concepção de homem. Ao dividir o homem em duas dimensões opostas, como defendiam os pensadores ingleses, Diderot dá à razão uma importância que se sobrepõe aos sentimentos. A razão traria aos indivíduos uma retidão para a vida que as paixões não poderiam oferecer. A expressão dessa razão viria sob a forma da vontade geral, que conduziria o indivíduo pelo melhor caminho.

Essa postura de Diderot, à qual Rousseau se opõe, esvazia uma das dimensões do indivíduo, que é a dimensão dos sentimentos e das paixões. Se Rousseau comtemplasse a tendência de Diderot, haveria o esvaziamento do sentimento do amor de si na vida do indivíduo cidadão. O que isso significa? Qual o desdobramento da separação entre a vontade geral e os sentimentos do indivíduo? Isso é possível para Rousseau? Quem acompanha a visão de Rousseau sobre o homem, percebe que tal separação não é possível. Não é possível ao indivíduo aderir a uma vontade comum, a uma vontade geral quando esta mesma vontade não condiz com seus sentimentos, com seu sentimento de existência. Portanto, se o sentimento de existência fundamental para o indivíduo é o amor de si, como querer exigir a negação do mesmo, se esse sentimento responde pelo elemento básico de sua sobrevivência? Isso só seria possível ao indivíduo, se ele negasse a sua própria constituição e, assim, descartasse uma parte de si. Mas a vontade geral seria uma resposta ao que é essencial ao homem, que é o sentimento de existência expresso pelo amor de si, o desejo de autorrealizar-se e que, num primeiro momento, correspondeu à sobrevivência; com a vontade geral, o sentimento de existência se confirmaria pela escolha dos indivíduos de partilhar o mesmo espaço, o espaço público. É esse espaço que serviria para o indivíduo se realizar, sob a orientação da vontade geral, que fosse a expressão da sua própria natureza. Nesse sentido é que Rousseau se distancia de Diderot, pois a vontade geral rousseauniana foge ao receituário meramente metafísico, àquilo que é estranho aos 
indivíduos, e que é algo puramente condutor. Uma vontade geral exterior ao indivíduo funcionaria como uma força externa à comunidade, que regularia a vida da forma mais perfeita possível, uma espécie do Leviatã hobbesiano. Seria uma construção formulada a partir de um mero processo racional, e desse tipo de concepção Rousseau quis se afastar, rejeitando uma leitura meramente racionalista da vontade geral (p. 33).

Inúmeros leitores de Rousseau o enquadram numa perspectiva racionalista de vontade geral, justamente por negarem o preceito primeiro da natureza humana, o preceito de conservação. Projetam a vontade geral como um feito de um processo racionalista. ${ }^{6}$

Eric Weil (1991) reconhece a importância dos sentimentos no pensamento de Rousseau, embora levante dúvidas sobre a centralidade dos mesmos, sobretudo em relação às questões da vida pública. Os sentimentos são importantes, dentro de um contexto da obra de Rousseau, mesmo que limitados a um certo grau da reflexão. A postura de Weil é a marca da tradição que transformou Rousseau em racionalista. Derathé, citado por Weil, confirma a mesma tese, sobre a qual ele se apoia.

Ao contrário do que geralmente se interpreta sobre a vontade geral de Rousseau, devese encontrar na mesma não apenas a mera dinâmica da racionalidade. A vontade geral rousseauniana, apesar do aspecto de unidade, é a unidade dos opostos da estrutura do indivíduo, que são os sentimentos e a razão, polos que aparentemente parecem se excluir. A tensão entre os polos do indivíduo é parte de sua própria constituição e lhe permite ser dinâmico. Para Rousseau, a relação entre razão e sensibilidade não anula um desses dois elementos. É a relação entre esses componentes que viabiliza a vida do indivíduo, e o faz ser o que ele é: um ser dinâmico que se refaz ao longo de sua vida. Ao olhar para a obra de Rousseau, pode-se verificar a centralidade do indivíduo em todo o seu percurso intelectual. Nesse sentido, o segundo Discurso tem um papel central. A história para Rousseau é a própria história das transformações pelas quais o indivíduo passou. Assim, mantém em suas análises da sociedade a tensão permanente das estruturas do indivíduo. Seu pensamento é marcado por polaridades constantes como: indivíduo/coletivo, sentimentos/razão, vontade particular/vontade geral etc. No caso específico da vontade geral, a regra se mantém. Ou seria possível retirar da vontade geral os elementos da sensibilidade do indivíduo? A vontade geral seria o mero aspecto racional do homem, que o guiaria pelo melhor caminho? Assim sendo, não se teria uma exclusão de uma dimensão do próprio indivíduo? Por que a tendência racionalista da vontade geral deveria

\footnotetext{
${ }^{6}$ Há diversos autores que podem ser indicados como defensores de uma vontade geral rousseauniana racionalista: Eric Weil, Jean-Fabien Spitz, Roger Masters, etc.
} 
predominar em Rousseau? Não pareceria uma contradição, já que ele não o faz na sua própria concepção de indivíduo? Essa tendência racionalista criaria uma vontade que estaria para além das imperfeições da vida do indivíduo, seria uma força que, não estando contaminada pelas imperfeições da vida, poderia conduzir os indivíduos por um caminho que os impedisse de desenvolver vontades egoístas, as quais poderiam colocar em perigo as estruturas da república. Esse tipo de interpretação racionalista da vontade geral poderia desenvolver um tipo de mentalidade totalitarista e arbitrária sobre a vontade geral de Rousseau. As interpretações racionalistas da vontade geral de Rousseau alimentaram uma leitura errônea sobre o filósofo genebrino. Somente uma entidade ou um estado perfeito, que conduzem pelo melhor caminho os indivíduos, podem se transformar em sistemas repressores. A perspectiva de vontade geral de Rousseau caminha pelo campo de sua polaridade, articula em sua constituição a razão e a sensibilidade. E esta é a expressão do amor de si. Como poderia se captar esse sentimento na vontade geral?

Isso pode ser captado de duas formas: pelo sentido de preservação e pelo sentido de envolvimento com a mesma. Em Do contrato social, Rousseau apresenta um contrato que possibilitaria a realização do indivíduo. O sentido de preservação e o sentido de envolvimento dariam à vontade geral a base do sentimento de existência do indivíduo. Aliado a isso se teria o componente da racionalidade, responsável pela elaboração do projeto que estruturaria o contrato de forma efetiva. Assim, a razão não apareceria como um mero guia, mas como algo que é condicionado por aquilo que os indivíduos almejam. Toda e qualquer forma de contrato que pretendesse viabilizar a realização dos indivíduos deveria ter como princípio básico de suas estruturas a constituição do próprio indivíduo. A vontade geral seria um ponto de convergência das individualidades. E que ponto de convergência seria esse? A total anulação da dependência entre os indivíduos e, em decorrência disso, a ausência da desigualdade. Dessa forma, percebese que, ao não se anular o indivíduo, não se anulam os seus sentidos, tampouco o amor de si. Se, por um lado, a sociedade seria a adesão do indivíduo a um projeto coletivo, por outro, essa adesão não anularia a inteireza das individualidades.

\footnotetext{
Mas, além da pessoa pública, temos de considerar as pessoas particulares que a compõem, e cuja vida e liberdade naturalmente independem dela. Trata-se, pois, de distinguir os direitos respectivos dos cidadãos e do soberano, e os deveres que os primeiros devem desempenhar na qualidade de súditos, do direito natural de que devem gozar na qualidade de homens (p. 48).
}

Pode-se ler a proposição de contrato de Rousseau a partir de duas dimensões: a espiritual e a prática. A dimensão espiritual corresponderia à vontade geral, dimensão aqui já apresentada. Extremamente importante, ela revela a força que dá unidade ao pacto. No entanto, além da 
vontade geral, o pacto rousseauniano necessita de uma estrutura que acolha os anseios dos indivíduos traduzidos pela vontade geral. E, como a vontade geral, essa estrutura de acolhimento não pode ser algo apartado do indivíduo. Assim, as estruturas do pacto conteriam uma dimensão racional e uma dimensão do sentimento de existência. A dimensão do sentimento poderia ser apontada como o elemento do poder legislativo, e a dimensão racional, a do poder executivo. $^{7}$

O princípio da vida política reside na autoridade soberana. O poder legislativo é o coração do Estado; o poder executivo, o cérebro que dá movimento a todas as partes. $\mathrm{O}$ cérebro pode paralisar-se e o indivíduo continuar a viver. Um homem torna-se imbecil e vive, mas desde que o coração deixa de funcionar, o animal morre (p. 102103).

Rousseau procura dar à estrutura da república a mesma constituição presente no indivíduo. Há uma relação entre sua antropologia e sua concepção política, embora tenham suas especificidades. Não há a separação entre aquilo que o indivíduo é e o que ele projeta para si, no caso específico, a república. Todo o capítulo onze, livro III, Do contrato social, que tem como título "Da morte do corpo político", retrata a humanidade que há nas criações do homem:

Tal é a tendência natural e inevitável dos governos, mesmo dos mais bem constituídos. Se Esparta e Roma pereceram, que Estado poderá durar para sempre? Se quisermos formar uma instituição duradoura, não pensemos, pois, em torná-la eterna. Para ser bem sucedido não é preciso tentar o impossível, nem se iludir com dar à obra dos homens uma solidez que as coisas humanas não comportam (p. 102).

O estado se revelaria pela sua vocação em acolher seu criador. De forma direta, Rousseau responde sobre qual seria a finalidade da associação política: "a conservação e a prosperidade de seus membros" (p. 98). Ao referir-se, também, a qual seria o melhor governo, se reporta ao que se pode tomar como referência para se avaliar essa esfera do estado, isto é, não é a capacidade intrínseca dos membros do governo que pode avaliá-lo como bom ou ruim, mas, sim, a forma como o governo se relaciona com o povo:

\begin{abstract}
Quando, pois, se pergunta, de modo absoluto, qual é o melhor Governo, faz-se uma pergunta tão insolúvel quanto indeterminada ou, em outras palavras, ela tem tantas boas soluções quantas combinações possíveis há nas posições absolutas e relativas dos povos. Mas, quando se perguntasse quais são as características pelas quais se pode conhecer se um dado povo é bem ou mal governado, então seria diferente e a questão poderia de fato ser resolvida (p. 98).
\end{abstract}

Além disso, como o indivíduo está em constante transformação, o mesmo deve ocorrer com o estado, que não deve ser eterno e absoluto, na medida em que o indivíduo também não

\footnotetext{
${ }^{7}$ A abordagem utilizada por Vincenti (2001, p. 144-145) permite um novo olhar sobre a constituição das estruturas do pacto social. Ele busca compreender a estrutura do indivíduo, a fim de tematizar a proposição de república em Rousseau. Dessa forma, compreende que a proposição do pacto leva em consideração, não apenas o aspecto racional do indivíduo, mas também a constituição do seu sentimento.
} 
o é. Se os indivíduos se transformam, e o estado e suas estruturas não se adequam a esse movimento, é que ele perdeu seu horizonte fundamental e tenderá a se voltar contra os indivíduos. Os homens poderiam, por meio de suas ações, dar uma vida mais longa ao estado, visto que o estado não se perpetuaria por si próprio ou pelas leis, mas subsistiria pela força do poder legislativo, pela força dos homens reunidos em assembleia. É graças a esse poder legislativo que o estado respiraria e se moveria. Ele seria a expressão coletiva do sentimento de existência dos indivíduos, o que, na vida contratual, é expresso pelo sentimento de amor à pátria, sentimento que tem ligação com o sentimento do amor de si. Portanto, sem o legislativo, sem a dinâmica existencial dos indivíduos, no caso específico, dos indivíduos cidadãos, o estado seria uma estrutura morta.

Além disso, há um elemento que antecede o poder legislativo e que se efetiva quando da elaboração do pacto e de suas estruturas: a vontade do conjunto de indivíduos de elaborar um pacto social. Seria possível, após a construção do pacto, os indivíduos eliminarem da via social seus sentidos e sentimentos? Se o pacto ganhou vida pela vontade do indivíduo, haveria como se desfazer dela? Em Rousseau, a resposta é negativa. Há diversas passagens que reforçam essa via interpretativa. A obra, Do contrato social, quarto capítulo, livro II, ao comentar os limites do poder do soberano, ressalta que esse não pode onerar os seus membros de forma indevida, o que deve ser levado em consideração não apenas sob a lei da razão, mas também pela lei da natureza.

O poder legislativo, que é a força do soberano, por sua vez, estaria em consonância com a vontade geral. Ela e o soberano deveriam formar uma unidade, e pela sua ação aquela se efetivaria. A articulação entre a vontade supracitada e a estrutura do pacto daria a conformidade necessária à república. Pode-se afirmar que a vontade geral, como parte da república, seria a sua dimensão espiritual (soberania); a dimensão prática seriam as estruturas constitutivas do pacto (soberano, leis, formas de governo, poderes executivo e legislativo). Ambas as dimensões da república rousseuniana são estruturadas a partir da constituição do próprio indivíduo cidadão. Quando da formação do pacto, surgiria o sujeito de direito. Não se trataria mais do indivíduo isolado, mas do indivíduo cidadão que tem no direito, a partir da formação da sociedade, o elemento que norteará sua nova vida. E um dos componentes fundamentais para a construção e a manutenção da vida em sociedade é o sentimento de existência, então um sentimento específico, o sentimento do amor à pátria. Somente as estruturas da república não garantiriam a sua manutenção. Rousseau procura preservar, em sua proposta de república, a 
razão e o sentimento de existência. Assim consta no mencionado capítulo quatro do livro II do seu Do contrato social ao tratar dos limites do poder soberano:

Mas, além da pessoa pública, temos de considerar as pessoas particulares que a compõem, e cuja vida e liberdade naturalmente independem dela. Trata-se, pois, de distinguir os direitos respectivos dos cidadãos e do soberano, e os deveres que os primeiros devem desempenhar na qualidade de súditos, do direito natural de que devem gozar na qualidade de homens (p. 48).

A república pregada por ele não seria uma mera projeção metafísica e racional, como alguns já afirmaram. Observe-se a seguinte disposição que corrobora a interpretação que aqui vem sendo adotada:

\begin{abstract}
A expressão é utilizada por Malebranche para designar o governo divino do mundo, mas o uso moral e político origina-se em Diderot, que o emprega antes de Rousseau, no artigo "Direito natural da Enciclopédia". Trata-se de uma vontade senão racional ao menos razoável, que envolve moral e política concernente ao gênero humano. Rousseau retoma o termo em um sentido muito próximo no artigo "Economia política". Mas sua doutrina evolui e, restringindo a noção à comunidade política, ele se afasta de Diderot desde o Manuscrito de Genebra, não mais considerando a razão mas o amor de si como fundamento daquilo que permite a cada indivíduo perceber nele mesmo o interesse comum e, assim, participar da elaboração da lei (VINCENTI, 2000, p. 60-61, tradução nossa). ${ }^{8}$
\end{abstract}

A república rousseauniana se manifestaria pela soberania e se projetaria em direção ao bem comum (princípio universal) que foi o desejo das individualidades contratantes. A dimensão prática da república (o soberano) em sua própria natureza é perpassada pelos sentidos de seus membros. Mais do que uma fórmula de estado, Rousseau apresenta princípios que poderiam nortear um projeto de vida coletiva. Um projeto que se constitui a partir da própria natureza humana e, por isso, perpassado de sentimentos e oscilações. A assembleia do povo seria a principal face da república, pois impulsionaria a vida da mesma. O povo em assembleia conduziria a própria perspectiva da vontade geral, seria o próprio coração da vida republicana. De nada adiantaria a cabeça, se o corpo viesse a morrer.

\title{
REFERÊNCIAS BIBLIOGRÁFICAS
}

ABBADIE, Jacques. L'art de se connaître soi-même ou la recherche des sources de la morale. Rotterdam: Chez Pierre Reinier Leers (1712). Texte revu par Christiane Frémont. Paris: Fayard, 2003.

\footnotetext{
8 “L'expression est pratiquée para Malebranche pour désigner le gouvernement divin du monde, mais l'usage moral et politique est issu de Diderot qui l'emploie avant Rousseau dans l'article "Droit naturel de l'Enccyclopédie". Il s'agit alors d'une volonté sinon rationnelle du moins raisonnable, qui enveloppe morale et politique et concerne le genre humain. Rousseau reprend le term en un sens très proche dans l'article "Économie politique". Mais sa doctrine évolue et tout en restreignant la notion à la communauté politique, il se sépare de Diderot dès le Manuscrit de Genève, pour ne plus voir la raison mais l'amour de soi au fondement de ce qui permet à chaque individu d'apercevoir en lui-même l'intérêt commun et de participer ainsi à l'élaboration de la loi."
} 
ARISTÓTELES. A política. Tradução de Roberto Leal Ferreira. 2. ed. São Paulo: Martins Fontes, 1998.

BACZKO, B. Rousseau, rousseauistes. In: ORY, Pascal (Dir.). Nouvelle histoire des idées politiques. Paris: Hachette, 1987, p. 92-104.

BURGELIN, Pierre. La philosophie de l'existence de Jean-Jacques Rousseau. Paris: PUF, 1952.

CANIVEZ, Patrice. Le sentiment et le politique: essai sur Hannah Arendt et Jean-Jacques Rousseau. Les Cahiers de Philosophie, Lille, n. 4, p. 53-80, automne 1987.

CASSIRER, Ernst. Le problème Jean-Jacques Rousseau. Tradução de Marc B. de Launay. Paris: Hachette, 1987.

CASSIRER, Ernst. Indivíduo e cosmos na filosofia do renascimento. Tradução do alemão de João Azenha Jr. Tradução do grego e do latim de Mario Eduardo Viaro. São Paulo: Martins Fontes, 2001.

Dictionnaire étymologique de la langue française. Sous la direction de Oscar Bloch et W. von Wartburg. Paris: Presses Universitaires de France, 1964.

GAUTHIER, David. Le sentiment d'existence. La quête inachevée de Jean-Jacques Rousseau. Traduit de l'anglais par Salim Hirèche. Genève: Markus Haller, 2011.

HOBBES, Thomas. Leviatã, ou Matéria, forma e poder de um estado eclesiástico e civil. Tradução de João Paulo Monteiro e Maria Beatriz Nizza da Silva. 4. ed. São Paulo: Nova Cultural, 1988. (Os Pensadores).

HONNETH, Axel. La lutte pour la reconnaissance. Traduit de 1'allemand par Pierre Rusch. Paris: Gallimard, 2000.

LOCKE, John. Carta acerca da tolerância; Segundo tratado sobre o governo; Ensaio acerca do entendimento humano (1690). Tradução de Anoar Aiex e E. Jaci Monteiro. 3. ed. São Paulo: Abril Cultural, 1983. (Os Pensadores).

LOCKE, John. Segundo tratado sobre o governo civil. Tradução de Magda Lopes e Marisa Lobo da Costa. Petrópolis: Vozes, 1990.

OLIVEIRA, Manfredo Araújo de. Ética e sociabilidade. São Paulo: Loyola, 1993.

ROUSSEAU, Jean-Jacques. Oeuvres complètes. Édition publiée sous la direction de Bernard Gagnebin et Marcel Raymond. Paris: Gallimard, 1959. 5v. (Bibliothèque de la Pléiade).

ROUSSEAU, Jean-Jacques. Émile ou De l'éducation. Chronologie et introduction par Michel Launay. Paris: Flammarion, 1966.

ROUSSEAU, Jean-Jacques. Do Contrato social. Tradução de Lourdes Santos Machado. 4. ed. São Paulo: Nova Cultural, 1987. (Os Pensadores).

ROUSSEAU, Jean-Jacques. Discurso sobre a origem e os fundamentos da desigualdade entre os homens. Tradução de Lourdes Santos Machado. 4. ed. São Paulo: Nova Cultural, 19871988a. (Os Pensadores).

ROUSSEAU, Jean-Jacques. Discurso sobre as ciências e as artes. Tradução de Lourdes Santos Machado. 4. ed. São Paulo: Nova Cultural, 1987-1988b. (Os Pensadores). 
ROUSSEAU, Jean-Jacques. Discurso sobre a economia política e Do Contrato social. Tradução de Maria Constança Peres Pissarra. Prefácio de Bento Prado Júnior. Petropólis, RJ: Vozes, 1995a.

ROUSSEAU, Jean-Jacques. Emílio ou Da educação. Tradução de Sérgio Milliet. 3. ed. Rio de Janeiro: Bertrand Brasil, 1995b.

ROUSSEAU, Jean-Jacques. Du contrat social. Présentation, notes, bibliographie et chronologie par Bruno Bernardi. Paris: Flammarion, 2001.

ROUSSEAU, Jean-Jacques. Carta a Christophe de Beaumont. Tradução de José Oscar de Almeida Marques. Campinas: IFCH/UNICAMP, 2004.

VINCENTI, Luc. Du Contrat Social. Rousseau. Paris: Ellipses, 2000. (Philo-Oeuvres).

VINCENTI, Luc. Jean-Jacques Rousseau: l'individu et la république. Paris: Kimé, 2001.

WEBER, Thadeu. Hegel, liberdade, estado e história. Petrópolis, RJ: Vozes, 1993.

WEIL, Eric. Jean-Jacques Rousseau et sa politque. Critique 56: Revue Générale des Publications Françaises et Étrangères, Paris, t. 9, n.56, p. 4-28, 1952.

WEIL, Eric. Essais et conférences. Tome 2 Politique. Paris : Vrin, 1991.

WEIL, Eric. Philosophie politique. Paris: Vrin, 2013.

WOKLER, Robert. Rousseau. Oxford: Oxford University Press, 1995.

ZARKA, Yves Charles (éd). Critique de la reconnaissance. Autour de l'oeuvre d'Axel Honneth. Paris : Éditions Mimésis, 2015.

ZARKA, Yves Charles. L'autre voie de la subjectivité. Paris: Beauchesne, 2000. 